\title{
Spatial ecology of Nassau grouper at home reef sites: using acoustic telemetry to track a large, long-lived epinephelid across multiple years (2005-2008)
}

\author{
Kayla M. Blincow ${ }^{1}$, Phillippe G. Bush ${ }^{2}$, Scott A. Heppell ${ }^{3}$, Croy M. McCoy ${ }^{2}$, \\ Bradley C. Johnson ${ }^{2}$, Christy V. Pattengill-Semmens ${ }^{4}$, Selina S. Heppell ${ }^{3}$, \\ Sierra J. Stevens-McGeever ${ }^{1}$, Leslie Whaylen ${ }^{4,5}$, Kirsten Luke ${ }^{6}$, Brice X. Semmens ${ }^{1, *}$ \\ ${ }^{1}$ Scripps Institution of Oceanography, University of California, San Diego, La Jolla, California 92093, USA \\ ${ }^{2}$ Department of Environment, Cayman Islands Government, Grand Cayman KY1-1002, Cayman Islands \\ ${ }^{3}$ Department of Fisheries and Wildlife, Oregon State University, Corvallis, Oregon 97331, USA \\ ${ }^{4}$ Reef Environmental Education Foundation (REEF), Key Largo, Florida 33037, USA \\ ${ }^{5}$ Flower Garden Banks National Marine Sanctuary, National Oceanic and Atmospheric Administration, Galveston, \\ Texas 77551, USA \\ ${ }^{6}$ Atlantic Coast Joint Venture, United States Fish and Wildlife Service, Panama City, Florida 32405, USA
}

\begin{abstract}
Characterizing the behavior of coral reef fishes at home reef sites can provide insight into the mechanisms of spatial ecology and provide a framework for spatial resource management. In the Caribbean, populations of Nassau grouper Epinephelus striatus have declined due to fishing impacts on spawning aggregations. Despite local and regional efforts by fisheries managers to implement regulations protecting spawning aggregations, few Nassau grouper populations appear to be recovering. In order to improve management strategies for this critically endangered species, it is necessary to understand the spatial ecology of the species across seasons and years. In the Cayman Islands, we used a multi-year, presence/absence, depth-coded acoustic tagging dataset of Nassau grouper to characterize patterns in the species' behavior and vertical habitat use at home reef sites. Twenty acoustically tagged individuals $(56-84 \mathrm{~cm}, 70.01 \pm 7.40 \mathrm{~cm}$; total length, mean $\pm \mathrm{SD}$ ) maintained consistent home reef sites, although some fish regularly shifted activity centers within the home site, often following a seasonal spawning migration. Seven fish with depth-coded tags showed a higher probability of vertical movement in the hours immediately following dawn and preceding dusk. We found evidence of a positive relationship between the fish condition factor and depth of home reef site. The finding of persistent home reef sites across years suggests that properly sized spatial reserves at home reef sites can be a useful complement to spawning aggregation protection when considering management strategies for Nassau grouper.
\end{abstract}

KEY WORDS: Grouper - Acoustic telemetry $\cdot$ Marine protected area $\cdot$ Movement $\cdot$ Ontogeny

\section{INTRODUCTION}

Home range, defined as the area over which an animal normally travels, is a critical part of understanding animal behavior and ecology (Burt 1943, Hayne 1949, Gerking 1953). In marine ecosystems,

\footnotetext{
*Corresponding author: bsemmens@ucsd.edu
}

some fishes migrate long distances to attend spawning aggregations, which expands their home range; however, many of these species have a limited range during non-spawning periods (Sadovy \& Eklund 1999, Starr et al. 2007, Legare et al. 2011). In this study we refer to the areas occupied by fish outside

(C) The authors 2020. Open Access under Creative Commons by Attribution Licence. Use, distribution and reproduction are unrestricted. Authors and original publication must be credited. 
of spawning season as 'home reef sites'; i.e. a subset of total home range area. For demersal fishes, understanding the connection between ecology and management requires gathering information on their behavior in relation to use of space in the short and long term. Demersal fishes commonly maintain defined home reef sites, occupying specific areas during daily activities. Food availability, population density, habitat features, and intra- and inter-specific interactions can influence behavior at these sites (Hixon \& Beets 1989, Maher \& Lott 2000, Pillans et al. 2017). Thus, home reef site dynamics can provide insight into space use, resource partitioning, habitat selection, and behavior of fish (Bolden 2001, Khan et al. 2017, Pillans et al. 2017, Farmer \& Ault 2018). Documenting these dynamics is also helpful in building effective spatial conservation and management policies, as the degree of movement of a given species can influence the effectiveness of such strategies (Kramer \& Chapman 1999, Crossin et al. 2017, Farmer \& Ault 2018).

Early studies on fish movements typically relied on fisheries-dependent mark-recapture studies (Rounsefell \& Kask 1945, Bardach 1958, Matthews 1990), with tagging providing long-term (multi-year) information on spatial use patterns. However, these studies require the recapture, or re-sighting if using diver surveys (e.g. Shapiro et al. 1994), of tagged animals and have limitations in characterizing fish behavior over fine spatial and temporal scales. Furthermore, these studies only provide straight-line estimates of movement between capture and recapture points. More recently, researchers have used acoustic tagging to characterize the fine-scale movements of fish in relation to marine protected area (MPA) boundaries (e.g. Zeller 1997, Parsons et al. 2003, Topping et al. 2005, Farmer \& Ault 2018), showing the importance of the relationship between MPA size and size of home reef sites when protecting fish. Other related studies provide evidence of nuance within home reef sites, with some fish shifting activity centers within these sites across time (e.g. Parsons et al. 2003) or showing habitat preferences as a function of body size (e.g. Topping et al. 2005).

The Nassau grouper Epinephelus striatus (Bloch, 1792) (Perciformes: Epinephelidae) is an ecologically and economically important large-bodied fish from the tropical Western Atlantic that undergoes ontogenetic shifts from larval to adult stages (Carter et al. 1994, Rudd \& Tupper 2002, Legare et al. 2011, Waterhouse et al. 2020). Planktonic larvae settle into nearshore seagrass and algal habitats as juveniles and shift to predominantly reef habitat as they grow (Sadovy \& Eklund 1999, Claydon \& Kroetz 2008).
Most individuals reach reproductive maturity by 7 to 8 yr of age (Bush et al. 2006), at which point they typically maintain and defend home reef sites on forereef areas (Sadovy \& Eklund 1999). There is some evidence that larger individuals tend to occur in deeper reef environments (Randall 1962, Sadovy \& Eklund 1999, Legare et al. 2011), and Semmens et al. (2008) suggested that this might be indicative of adult ontogenetic sorting.

The Nassau grouper is categorized as Critically Endangered by the International Union for Conservation of Nature Red List of Threatened Species (Sadovy et al. 2018), and as Threatened under the United States Endangered Species Act (81 FR 42268, June 29, 2016). It is vulnerable to fishing because of intensive targeting and exploitation of spawning aggregations, which form consistently during winter months at specific reef locations (Smith 1961, Sadovy \& Eklund 1999, Sala et al. 2001, Semmens et al. 2008). Consequently, many Nassau grouper spawning aggregations have disappeared throughout the Caribbean (Sadovy 1999, Sala et al. 2001, AguilarPerera 2006). Given that Nassau grouper aggregations are at risk, much of the research surrounding this species concentrates on these gatherings (e.g. Jackson et al. 2014, Dahlgren et al. 2016, Egerton et al. 2017, Stump et al. 2017, Waterhouse et al. 2020), and management for population recovery focuses on protecting these aggregations through seasonal and/or spatial fishing closures (Chiappone et al. 2000, Bush et al. 2006, Benedetti 2013, Waterhouse et al. 2020). However, there are few documented cases of population recovery following overfishing (Kadison et al. 2010, Waterhouse et al. 2020), which suggests additional management strategies might be necessary (Semmens et al. 2008, Grüss et al. 2014, Egerton et al. 2017, Waterhouse et al. 2020).

Expanding place-based management beyond protecting spawning aggregations requires an understanding of the demography and behavior of Nassau grouper outside of the spawning season. The behavior and habitat use of adult individuals during the non-spawning season are not well described. Bolden (2000) characterized the home reef sites of 22 individuals after continuously tracking them in the Bahamas for $3 \mathrm{wk}$. The findings from that study were enlightening but covered a relatively short time scale. Dahlgren et al. (2016) found Nassau grouper show high site fidelity to home reefs after tracking them for multiple years, but did not characterize the behavior of fish at these home reef sites. Similarly, Starr et al. (2007) found high site fidelity to home reef sites in tagged Nassau grouper, but again the bulk of 
their analysis concerned movements and behavior associated with spawning aggregations.

The objective of this study was to document the spatial ecology of Nassau grouper at home reef sites to aid management decisions for this species outside of spawning aggregation-based measures. We used long-term acoustic tag data records from reproductive-aged Nassau grouper in the Cayman Islands to describe the behavior of these fish at home reef sites across multiple years. These data were collected as part of the Grouper Moon Project, a collaborative fisheries research and monitoring program coordinated by the Reef Environmental Education Foundation (REEF) and the Cayman Islands Department of Environment (DoE), which aims to develop effective, science-based conservation and management strategies for Nassau grouper in Cayman waters. Using presence/absence and depth data from acoustic tags, we characterized patterns in detections at receivers within home reef sites and vertical habitat use in relation to explanatory variables including diurnal cycles and the condition factor of tagged individuals.

\section{MATERIALS AND METHODS}

\subsection{Acoustic tagging methods}

Between 2005 and 2008, we tagged 82 adult Nassau grouper on Little Cayman and Cayman Brac,
Cayman Islands (our Fig. 1; Semmens et al. 2007) using 2 Vemco® V16 coded transmitter tag types: (1) Vemco ${ }^{\circledR}$ V16-4H coded tag, or (2) Vemco ${ }^{\circledR}$ V16P-4H depth-coded tag (depth range of 0 to $204 \mathrm{~m}$ ). Both tag types had a randomized 60 to $180 \mathrm{~s}$ reporting interval and a $1400 \mathrm{~d}$ battery life, resulting in detection records from 2005 to 2011. The V16-4H tags provided only presence information if detected by a receiver, while the V16P-4H tags provided both presence and depth of the tagged fish. For consistency during this work, we refer to the V16-4H tags as non-depth-coded tags and the V16P-4H tags as depth-coded tags.

We caught Nassau grouper using 3 methods: hand lines, baited Antillean fish traps, and diver capture with a mesh bag. However, we quickly abandoned the use of Antillean fish traps due to isopod infestation of trapped fish (Semmens et al. 2006). We typically equipped hand lines with 12/0 circle hooks, $0.5 \mathrm{~kg}$ weights and a combination of fresh reef fish and squid as bait. Fish were caught at depths of approximately $30 \mathrm{~m}$ and brought slowly to the surface to minimize barotrauma. Outside of the spawning season, divers captured grouper by locating and chasing individuals into crevices in the reef. For diver capture, divers sedated fish using $500 \mathrm{ml}$ of a 1:500 quinaldine/seawater solution applied into the water surrounding the fish. In some cases, the fish swam out into a mesh bag; in other cases, the fish was removed by hand and placed in a mesh bag then subsequently brought to the surface for tagging.

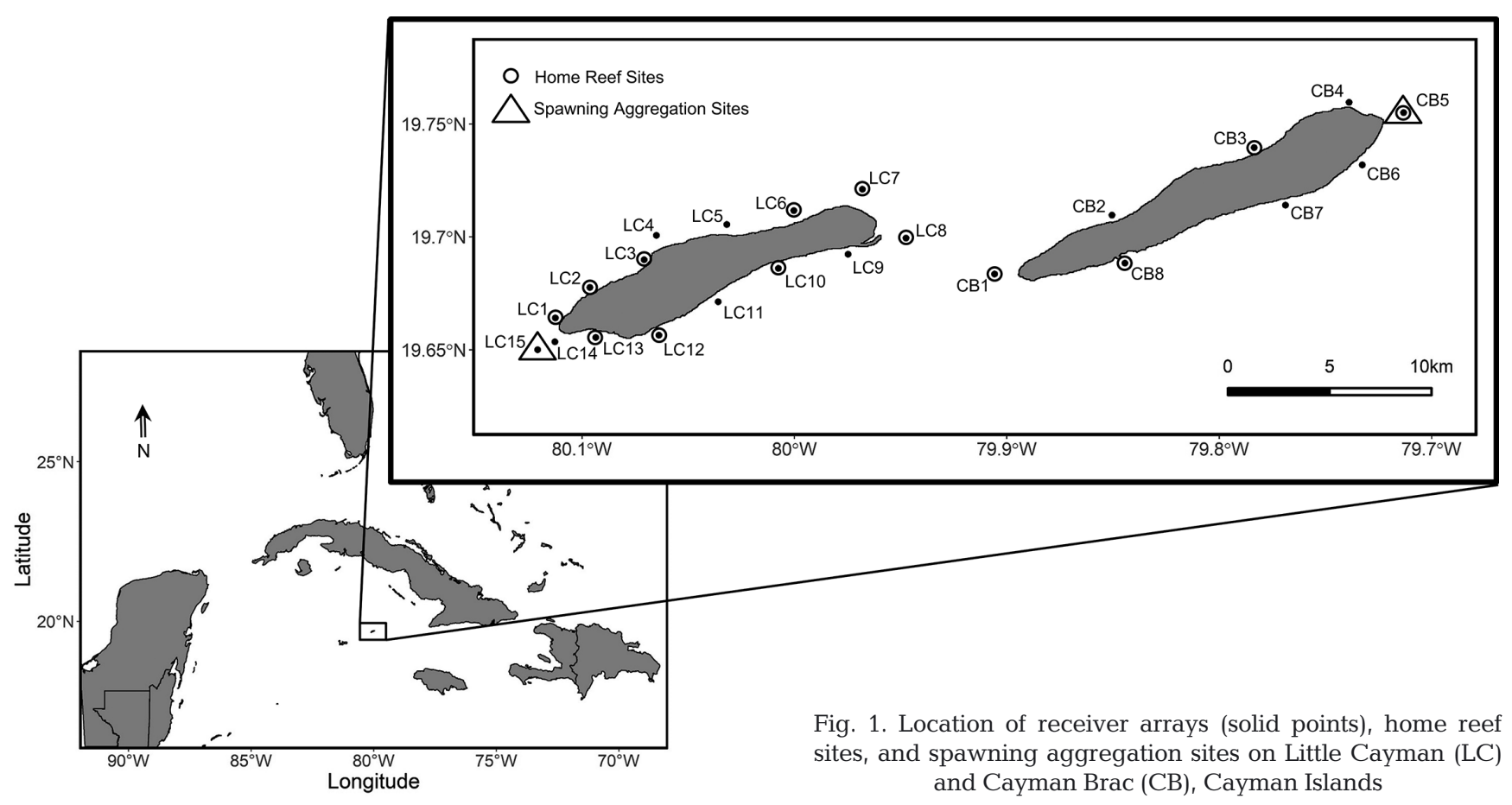


We measured each fish for total length $(\mathrm{cm})$ and weight $(\mathrm{kg})$, and then surgically implanted a V16 or V16P coded transmitter. Tagging procedures have been described by Semmens et al. (2007). We released all fish at their capture site using a weighted hook recompression line or by hand-transporting the fish in a mesh bag for release on the bottom. The Cayman Islands Marine Conservation Board provided permits to conduct tagging, and the University of California, San Diego Institutional Animal Care and Use Committee approved our tagging protocols.

On Little Cayman, we tagged 30 fish (5 depthcoded tags and 25 non-depth-coded tags) at the west end spawning aggregation site during the 2005 spawning season (Receiver LC15; Fig. 1), and subsequently tagged 20 fish with non-depth-coded tags at various sites around the island in the spring and summer of the same year. On Cayman Brac, we tagged 11 fish with non-depth-coded tags at various sites outside of spawning season in 2006, and used the detections of those tagged individuals to locate an aggregation on the eastern end of the island during the subsequent spawning season (early 2007) (Receiver CB5; Fig. 1). During the 2008 spawning season we tagged 21 individuals (8 depth-coded tags and 13 non-depth-coded tags) at the Cayman Brac spawning site. All tagged fish ranged in size from 45 to $84 \mathrm{~cm}$ in total length $(66.29 \pm 8.09 \mathrm{~cm}$; mean $\pm \mathrm{SD})$ and 1.5 to $12.5 \mathrm{~kg}$ in weight $(5.92 \pm 2.64 \mathrm{~kg})$.

We used stationary receiver arrays deployed on both Little Cayman and Cayman Brac to track tagged fish movements over time (Fig. 1). The Little Cayman array comprised 15 Vemco® VR2 single channel passive autonomous data-loggers placed at approximately $2 \mathrm{~km}$ increments. The Cayman Brac array comprised 8 VR2 receivers spaced at approximately $4 \mathrm{~km}$ increments. Each VR2 receiver logged date, time, individual ID, and depth (depth-coded tags only) when a tag reported within range of the receiver.

We estimated the detection range of the VR2 receivers by towing a Vemco®-coded transmitter tag ( $\sim 1$ to $2 \mathrm{~m}$ depth) behind a boat and navigating around a moored acoustic receiver in the study region (Receiver LC13; Fig. 1). All pings (i.e. acoustic tag transmissions) during mobile tracking were recorded by a Vemco® VR100 mobile receiver unit deployed off the boat in close proximity to the tag. We compared the VR100 detections with the recorded detections on the moored VR2 receiver ( $6 \mathrm{~m}$ depth; similar for all VR2 moorings). Using coordinates for each ping detection on the VR100, we calculated the distance $(\mathrm{m})$ of each ping from the VR2 receiver. We analyzed these data using a generalized linear model with a logit link to establish a relationship between the detection probability of individual pings (binary response) and distance of the tag from the receiver (continuous covariate). We considered the detection range of our receivers to be the distance at which we detected tag pings with a $50 \%$ probability. We note that previous studies demonstrate that detection range varies depending on assorted environmental factors, such as diurnal noise patterns or current variability (e.g. Mathies et al. 2014, Huveneers et al. 2016); however, for the purposes of this study we make the simplifying assumption of a relatively constant detection range over time.

\subsection{Analysis}

We used receiver detections of tagged fish from both islands in our analysis. The length of tag detections for each fish varied from a few mo to $3 \mathrm{yr}$. Unless otherwise specified, we performed all analyses using R statistical software, version 3.6.1 (R Core Team 2019).

Due to the generally sparse structure of our receiver array, we were unable to calculate traditional home range metrics for our tagged fish; however, we were able to infer patterns in home reef site use based on changes in depth and detection frequency in cases where fish occupied home reef sites that overlapped with the detection ranges of our receivers. To determine which tagged fish maintained home reef sites near fixed VR2 receivers we identified all of the fish with consistent detections at a single 'home' receiver for at least 3 mo outside of the spawning season (peak spawning months of January and February). For these fish, we assumed that the receiver detection area overlapped with the individual's home reef site. We explored using more traditional acoustic telemetry indices to identify home receivers, such as a residency index (the number of days a fish was detected at a given receiver divided by the total number of days a fish was detected; Abecasis et al. 2009, Afonso et al. 2012, Fontes et al. 2014). We chose not to use this type of metric, because it required us to set an arbitrary limit for what value of the index constituted a true home receiver and it was not intuitive where that cut off should lie. Ultimately, we chose to use the 3 mo filter method described above, because it was a more intuitive and conservative metric. We classified 20 fish as having home reef sites near a fixed VR2 station, 6 of which were depthcoded and 14 of which were not. We limited the rest 
of our analyses to these 20 individuals with the exception of the inclusion of 1 additional fish with a depth-coded tag in our vertical activity analysis (described below). This latter fish did not meet our requirements for a home receiver, but had consistent detections outside of the spawning season that we felt warranted inclusion in the activity analysis.

For fish with non-depth-coded tags, we visualized changes in their long-term activity by plotting the daily number of detections recorded at their home receiver, including a moving average of the daily detections spanning $20 \mathrm{~d}$ (see Fig. S1 in Supplement 1 at www.int-res.com/articles/suppl/m655 p199_supp1.pdf). For fish with depth-coded tags, we additionally analyzed the depth ranges occupied by a single fish at its home receiver through time by plotting the depth for each tag detection at that receiver. To better visualize the change in depth through time, we calculated a moving depth average spanning 20 consecutive depth detections. We subsequently evaluated these plots to determine if persistent changes in the daily number of detections at the home receiver was linked to persistent changes in depth, and thereby could be indicative of shifts over time in activity centers at the home reef site.

In accordance with previous studies on fish movement (e.g. Holts \& Bedford 1993, Andrews et al. 2009), we generated a vertical activity index as a means of analyzing diel movement within the water column during the non-spawning season. To calculate the activity index, we first filtered the detection data for every fish with a depth-coded tag $(n=13)$ to include only detections that occurred within an hour of each other. After the filtering process, we were left with 7 fish with enough detections to conduct the analysis. These fish included the 6 individuals previously identified as having a home receiver plus 1 additional individual. We generated the activity index for these 7 fish by finding the absolute value of the change in depth between consecutive detections and dividing it by the time between detections. We grouped each activity index based on the hour of the day at which the movement occurred. To aid in visualization and interpretation of time of day effects, we categorized each hour of the $24 \mathrm{~h}$ period as day, night, or crepuscular, based on the National Oceanic and Atmospheric Administration's (NOAA) records of sunrise, sunset, and astronomical twilight in the Cayman Islands. To look for patterns in the magnitude of fish movement in each hour of the day, we selected all instances in which fish changed depth by filtering for positive activity indices, thereby removing all cases of zero movement. We also calculated the probability of vertical activity for each hour by converting the activity indices into a binary response variable (i.e. either the fish moved or it did not). We used a Bayesian delta-generalized linear mixed model (delta-GLMM) framework to test the effect of hour of day on the magnitude of vertical activity (how much fish moved) and the binary probability of vertical activity (whether fish moved or not) (Stefánsson 1996, Thorson \& Ward 2013).

We fit the magnitude of vertical activity data in log space using the following likelihood:

$$
\log \left(A_{i}\right) \sim \operatorname{Norm}\left[\log \left(E_{f, h}\right), \sigma_{f, h}\right]
$$

where $A_{i}$ is the magnitude of vertical activity for observation $i_{i} E_{f, h}$ is the expected magnitude of vertical activity for a given individual $f$ in a given hour $h_{\text {; }}$ and $\sigma_{f, h}$ is the standard deviation of the magnitude of vertical activity for a given individual $f$ in a given hour $h$. We treated hour of day as a fixed effect, and individual fish as a random effect. We estimated the expected magnitude of activity for each individual in each hour using the following relationship:

$$
\log \left(E_{f, h}\right) \sim \operatorname{Norm}\left[\log \left(\bar{\mu}_{\text {mag }_{h}}\right), \sigma_{\text {mag }_{h}}\right]
$$

where $\bar{\mu}_{\text {mag }_{h}}$ is the mean magnitude of vertical activity per hour across fish; and $\sigma_{\operatorname{mag}_{h}}$ is the standard deviation of the mean magnitude of vertical activity per hour across fish. We used the following priors in this model: a uniform distribution with bounds -10 and 10 for $\bar{\mu}_{\text {mag }_{h} ;}$ and a uniform distribution with bounds 0 and 10 for $\sigma_{\text {mag }_{h}}$.

We fit the probability of activity data using the following Bernoulli likelihood:

$$
M_{i} \sim \operatorname{Bernoulli}\left(p_{f, h}\right)
$$

where $M_{i}$ is the binary vertical movement for observation $i_{\text {; }}$ and $p_{f, h}$ is the expected proportion of movement observations for a given fish $f$ in a given hour $h$. We treated hour of day as a fixed effect, and individual fish as a random effect. We estimated the expected probability of movement in each hour using the following relationship:

$$
\operatorname{logit}\left(p_{f, h}\right) \sim \operatorname{Norm}\left(\bar{\mu}_{p r_{h}}, \sigma_{p r_{h}}\right)
$$

where $\bar{\mu}_{p r_{h}}$ is the mean probability of movement per hour across fish; and $\sigma_{p r}$ is the standard deviation of the probability of movement per hour across fish. We used the following priors in this model (in logit 
space): a normal distribution with mean of 0 and standard deviation of 0.304 for $\bar{\mu}_{p r_{h}}$ and a uniform distribution with bounds 0 and 10 for $\sigma_{p r}$.

We used JAGS software (Plummer 2003) and the rjags package (Plummer et al. 2019) to fit these models in $\mathrm{R}$ using Bayesian Monte Carlo Markov Chain (MCMC) sampling (R Core Team 2019). We ran the models using 3 parallel MCMC chains, each obtaining 350000 samples, the first 50000 of which were discarded as they were used to adapt the sampling algorithm. An additional 50000 were discarded as burn-in. We retained every 50th iteration of the remaining 250000 to reduce autocorrelation, resulting in an output of 5000 samples of the posterior distribution for each chain. We confirmed parameter convergence by evaluating density and trace plots using the mcmcplots package (McKay Curtis 2018), and the potential scale reduction factor (' $R$ hat') (Gelman \& Rubin 1992). The R and JAGS code for fitting these models can be found in Supplement 2 at www.int-res.com/articles/suppl/m655p199 _supp2.txt.

To test the relationship between depth and fish body size, we performed a simple Bayesian linear regression analysis comparing the mean depth of each of the 6 fish with depth-coded tags and a home receiver to the length, weight, and condition factor $(K)$ of the fish (based on data collected at the time of tagging; see Table 1). We calculated the condition of the fish using Fulton's condition factor equation (Ricker 1975):

$$
K=\frac{100 \times \text { weight }(\mathrm{g})}{\text { length }(\mathrm{cm})^{3}}
$$

The condition factor is a useful metric because it combines length and weight measures into a single, more holistic measure of the well-being of a fish. In general, there is a positive relationship between condition factor and other measures of fish health, such as thermal tolerance (Robinson et al. 2008) and gross energy content (Pangle \& Sutton 2005). The 6 individuals included in this depth-body size analysis were all tagged in January at their respective spawning aggregation sites, which allowed us to avoid any potential bias associated with higher condition of gravid individuals. For the purposes of this analysis, we assumed individuals maintained their condition throughout the sampling period. Using the blmeco package in R (Korner-Nievergelt et al. 2015), we calculated the Watanabe-Akaike information criterion (WAIC) to compare our linear models and determine which model-length, weight, condition factor, or intercept only — was most parsimonious.
We performed a spatial analysis comparing the depth range of detections at the home receiver to bathymetry data around the receiver for the 6 depthtagged fish with home receivers to identify areas each fish was most likely to occupy. Since Nassau grouper are considered demersal, we assumed that their depth records would closely track with the bathymetry of the reef. We used bathymetry data provided by DoE to perform the analysis using ESRI ArcGIS software. We first mapped the receiver arrays around Cayman Brac and Little Cayman, then overlaid those points onto the bathymetry map. We generated a $320 \mathrm{~m}$ buffer around each receiver denoting the detection range (based on the $50 \%$ detection probability threshold defined by the detection range analysis described above). We calculated the mean and standard deviation of depth records for each of the 6 fish with depthcoded tags at their respective home receivers. Using bathymetry data, we determined which areas within the detection range of the home receiver fish were likely to occupy by identifying areas within $\pm 1 \mathrm{SD}$ of the mean (most likely to occur here), $\pm 2 \mathrm{SD}$ of the mean (likely), and \pm 3 SD (less likely). There were some cases in which the depth range of the fish exceeded the extent of the bathymetry data provided by the DoE. To manage this issue, we classified any area of the receiver detection range that extended beyond the DoE data as deeper than the maximum depth of the bathymetric data. The Cayman Islands are marked by narrow continental shelves that drop sharply from depths of approximately 30-45 $\mathrm{m}$ to depths exceeding $300 \mathrm{~m}$ (Kobara \& Heyman 2008, Heyman \& Kobara 2012). Based on knowledge of environments preferred by Nassau grouper (Sadovy \& Eklund 1999, Starr et al. 2007), the characteristically steep shelf of the Cayman Islands (Kobara \& Heyman 2008), and our own experiences observing this species in the study area, we assumed that fish with depth ranges that exceeded the maximum available bathymetry data were equally likely to occupy a band of vertical wall habitat along the shelf tracking the deepest available contour. We believed it to be extremely unlikely fish would occupy areas beyond this extent. This analysis resulted in a map of the proportion of the home receiver detection range likely occupied by each fish given their depth records.

\section{RESULTS}

The network of receivers on Little Cayman and Cayman Brac collectively gathered over 6 yr of acoustic 
detections of tagged Nassau grouper from early 2005 to mid-2011. Based on the detection range test, the VR2 receivers detected tag pings with a $50 \%$ probability at $320 \mathrm{~m}$ (Fig. 2). In all subsequent analyses, we assumed this to be the nominal detection range of the receivers. On average, fish were detected for a period of $8 \mathrm{mo}$. The longest detection record for a fish with a non-depth-coded tag was $2.5 \mathrm{yr}$, while the longest detection record for a fish with a depth-coded tag was $3 \mathrm{yr}$. We identified 20 of the 82 tagged fish as maintaining a home reef site near a receiver. Fish with home receivers ranged in size from 56 to $84 \mathrm{~cm}$ in total length $(70.01 \pm 7.40 \mathrm{~cm}), 3.5$ to $12.5 \mathrm{~kg}$ in weight $(7.02$ $\pm 2.49 \mathrm{~kg}$ ), with condition factors ranging from 1.70 to 2.25 (1.96 \pm 0.13) (Table S1 in Supplement 1). Six of these individuals had depth-coded tags and ranged in size from 60 to $83 \mathrm{~cm}$ in total length $(69.45 \pm 3.82 \mathrm{~cm})$, 4 to $12.5 \mathrm{~kg}$ in weight $(6.80 \pm 1.55 \mathrm{~kg})$, and 1.78 to 2.19 in condition factor $(2.00 \pm 0.05)$ (Table 1). At least 4 of the 82 tagged fish were caught before the acoustic tags expired, based on returns from fishers. Of those, 2 had a home receiver.

Both fish with non-depth-coded tags (Fig. S1) and depth-coded tags (Fig. 3) demonstrated shifts in activity centers at their home receivers over time. For fish with non-depth-coded tags, this finding was evidenced by obvious and persistent shifts in the number of detections per day, suggesting fish were moving activity centers over time either away from or closer to their home receivers (Fig. S1). Similarly, fish with depth-coded tags showed persistent shifts in average depth at their home receivers over time (Fig. 3). When we compared the depth records with daily detection frequencies of the depthtagged fish, we found that both metrics displayed shifts at the same time points (Fig. 4). We took this as evidence that persistent shifts in daily detection frequencies likely reflect shifts in activity centers at the home reef sites in fish with non-depth-coded tags (albeit much more coarsely than depth records). Changes in activity centers happened almost exclu-

Table 1. Morphometric and tag data for the 6 Nassau grouper with depthcoded tags and home receivers that we used in the depth/size metric analysis

\begin{tabular}{|clcccc|}
\hline $\begin{array}{c}\text { Fish } \\
\text { ID }\end{array}$ & Detection period & $\begin{array}{c}\text { Home } \\
\text { receiver }\end{array}$ & $\begin{array}{c}\text { Total } \\
\text { length }(\mathrm{cm})\end{array}$ & $\begin{array}{c}\text { Weight } \\
(\mathrm{kg})\end{array}$ & $\begin{array}{c}\text { Condition } \\
\text { factor }\end{array}$ \\
\hline 41 & Jan 2005-Jan 2007 & LC3 & 70 & 6 & 1.78 \\
42 & Jan 2005-May 2006 & LC3 & 83 & 12.5 & 2.19 \\
43 & Jan 2005-Oct 2006 & LC13 & 62 & 5 & 2.10 \\
59 & Feb 2008-May 2008 & CB8 & 60 & 4 & 1.85 \\
61 & Jan 2008-Apr 2011 & CB3 & 68 & 6.25 & 1.99 \\
63 & Jan 2008-May 2008 & CB5 & 72 & 7.5 & 2.01 \\
\hline
\end{tabular}

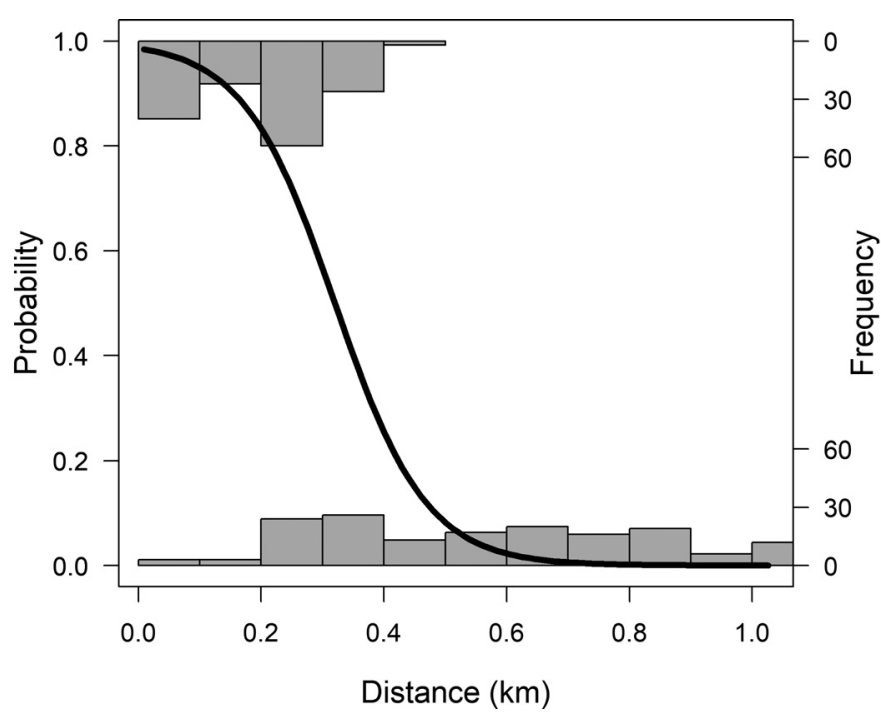

Fig. 2. Results of the Vemco V16 tag detection range analysis. Bar plots correspond to the right $y$-axis. Positive VR2 receiver detections are shown by the bars in the upper frequency plot, while negative (missed) VR2 detections are displayed in the lower frequency plot. The black line corresponds to the left $y$-axis and indicates the probability of detecting a tag at a given distance from the moored VR2 receiver. Based on model fit, the detection probability for the receiver is $50 \%$ at a distance of $0.32 \mathrm{~km}$

sively following the return of fish to their home receivers after a spawning event. No tagged fish were detected outside the island from which they were tagged (i.e. we found no evidence that fish moved between islands).

The analysis of vertical activity revealed no clear diel patterns in the magnitude of activity for the 7 fish with depth-coded tags included in this portion of the analysis (Fig. 5a); however, we found diel patterns in the binary probability of vertical activity (Fig. 5b). The 7 fish showed a higher probability of vertical activity during daylight hours, especially the first hours of daylight immediately following the morning crepuscular period, as well as leading up to and including the evening crepuscular period (Fig. 5b).

All of the linear models tested indicated a positive relationship between body size and depth for depth-tagged fish with home receivers. The WAIC model weights indicated that the condition model, which accounts for both length and weight in a single term, had greater support than the lengthor weight-only models (Table 2). Collectively, models that accounted for fish condition or size dominated nearly all the model weight relative to the 

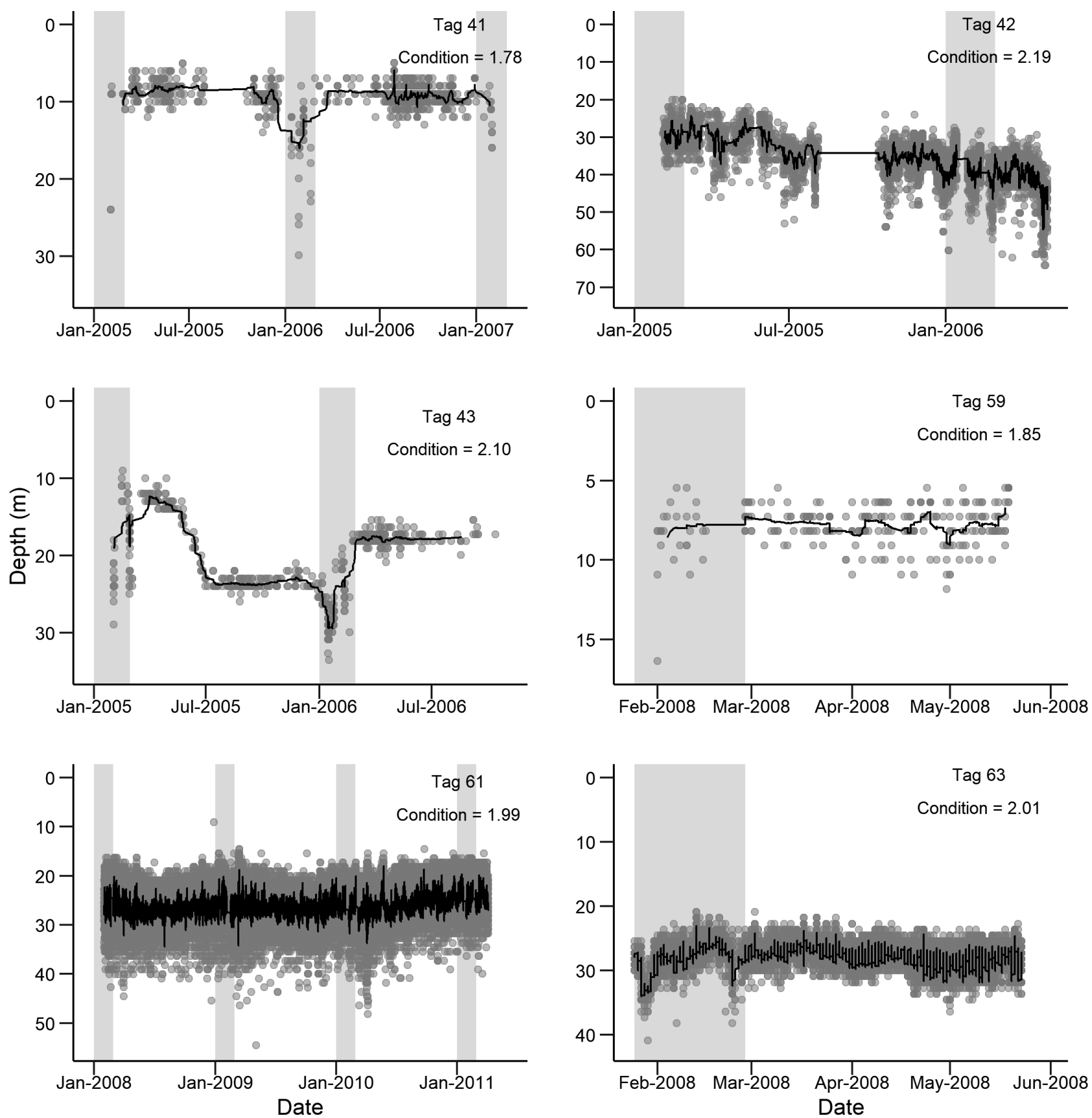

Fig. 3. Time series of home receiver detections for each of the 6 fish with depth-coded tags that we identified as having a home receiver. Gray areas: spawning months; black line: 20-consecutive detection moving average of depth in each plot. Note that depth on the $y$-axis and time on the $x$-axis are scaled to the individual plot based on the depths and detection period of each fish

intercept only model (Table 2), providing strong support for the notion that larger or higher condition animals occupy deeper habitat (Fig. 6).

The depth mapping analysis revealed that the 6 fish analyzed likely occupy a defined area within the detection range of their home receiver (Fig. 7). The fish with the highest condition values tended to occupy deeper habitats ( $>20 \mathrm{~m}$ ) along the reef edge, despite the availability of shallower habitats within the detectable range (Fig. 7). One receiver had 2 tagged residents within its detection range. We found no overlap between the regions likely occupied by the 2 fish at this home receiver. Of these 2 fish, the one with the higher condition value occupied deeper habitat available along the reef edge (Fig. 7e). 

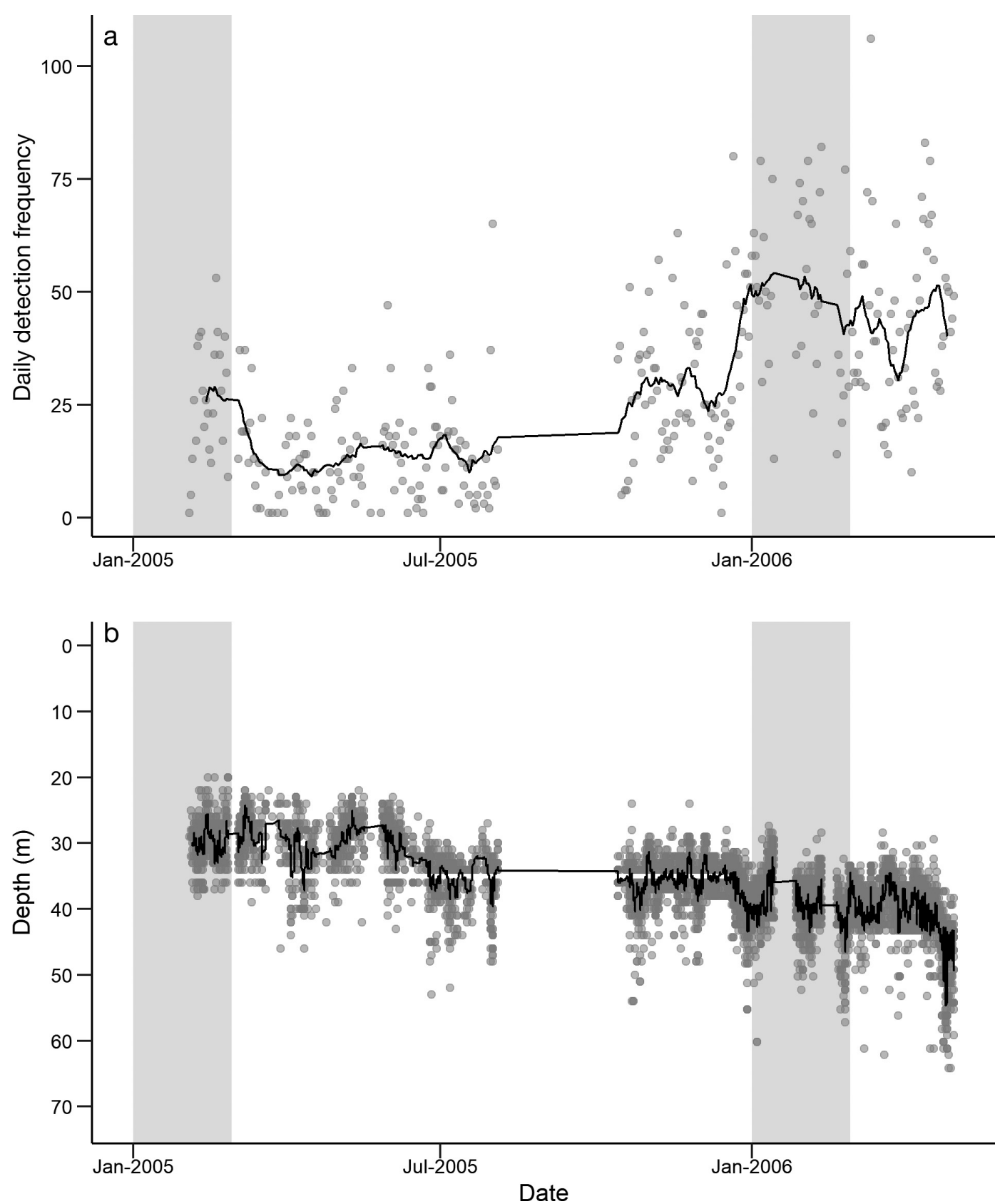

Fig. 4. Sample comparison plot of (a) daily home receiver detections and (b) depth records at the home receiver for Tag ID 42. Gray areas: spawning months; black line: 20-consecutive data point moving average in each plot. In general, persistent shifts in depth records of this fish correspond to persistent shifts in daily detection frequency at its home receiver

\section{DISCUSSION}

Many demersal marine fishes persistently occupy specific reef areas to maximize survival and reproduction (Zeller 1997, Bolden 2001). However, the persistence of behaviors at home reef sites over long periods (months to years) is poorly understood. Some spatial resources, such as refuge, are largely invariant to the ecosystem dynamics of home reef sites
(Hixon \& Beets 1993). Prey resources, however, can be dynamic and directly influenced by the impacts of the individual occupying a home reef (Hixon \& Beets 1993, Almany 2004). This dynamic may influence the quality of home reef sites over time and may impact the centers of activities within these sites, or even result in relocation. Our findings suggest that Nassau grouper vary activity centers at home reef sites over a long time period, but do not typically relocate their 

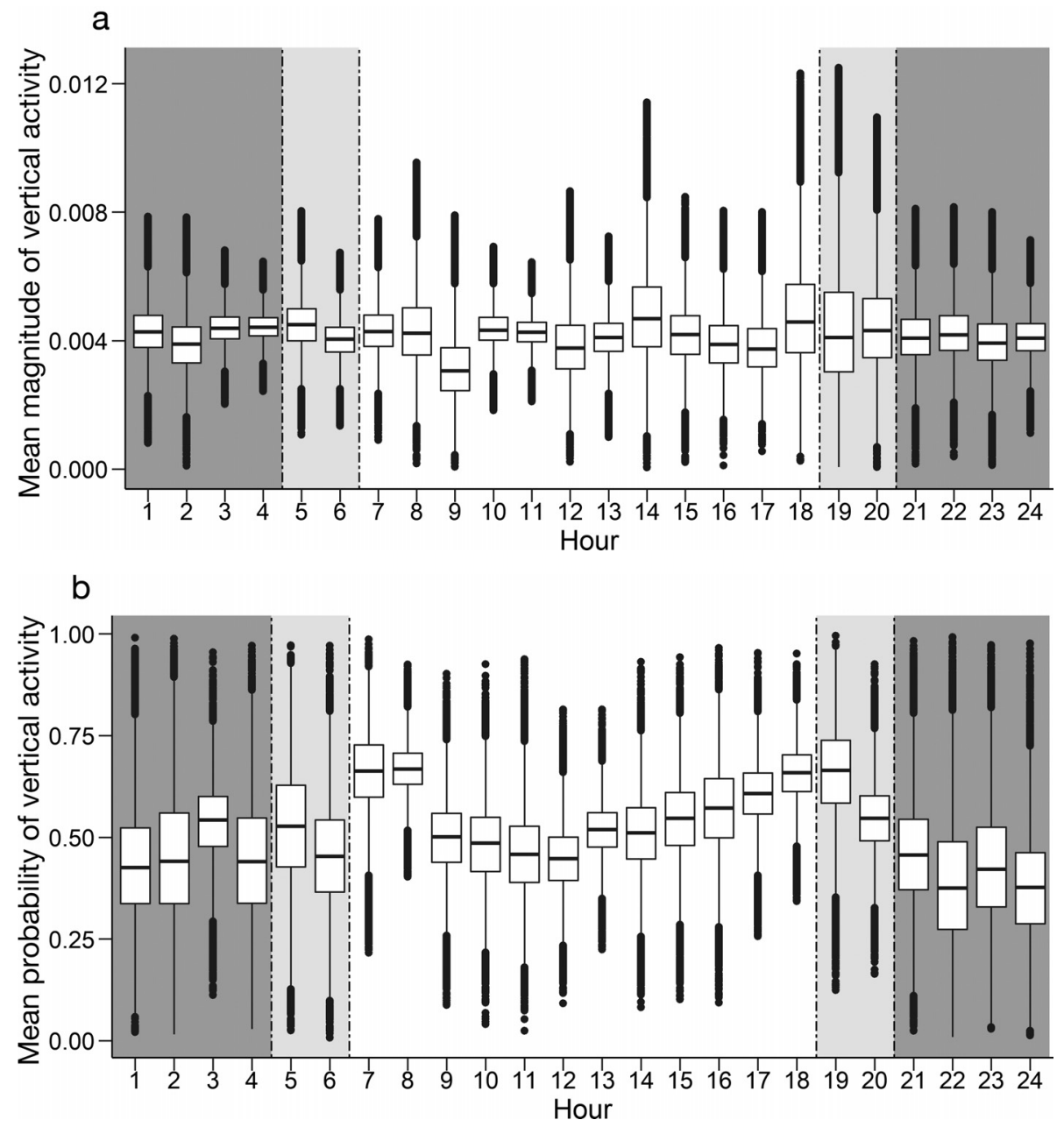

Fig. 5. Mean estimates of the (a) magnitude $\left(\bar{\mu}_{\text {mag }_{h}}\right)$ and (b) probability $\left(\bar{\mu}_{p r_{h}}\right)$ of vertical activity for each hour of the day across all depth-tagged fish that had a sufficient number of detections to be included in the analysis $(n=7)$. The solid horizontal line corresponds to median values, the upper and lower sections of the box outline correspond to the first and third quartiles, the whiskers extend to the highest and lowest values within 1.5 times the posterior draw interquartile range, and the dots correspond to outliers $>1.5$ times but $<3$ times the interquartile range beyond either end of the box. Dark gray areas: night hours; light gray areas: crepuscular hours; white areas: daylight hours

home reef sites between spawning seasons. None of the fish we tagged moved between islands, and outside of spawning migrations, most maintained a presence in the same reef area for the duration of their tag detection history. Our depth mapping analysis showed that even within the detection range of a home receiver, individuals are likely occupying smaller, more defined home reef sites (Fig. 7). Higher condition individuals seem to occupy deeper home reef sites (Fig. 6). Long-term changes in activity centers at home reef sites appear to occur most often in concert with seasonal spawning migrations. On a diel scale, we found that Nassau grouper have a higher probability of activity during crepuscular time windows (Fig. 5b).
Despite the ability of Nassau grouper to travel great distances to spawn (up to hundreds of kilometers in some parts of the Caribbean; Carter et al. 1994, Bolden 2000, Sherman et al. 2016), we did not find evidence of this occurring in the Cayman Islands. Our results align with previous findings of high site fidelity following spawning migrations in this species (Starr et al. 2007, Dahlgren et al. 2016); however, we also found that tagged Nassau grouper shifted activity centers at home reef sites over time. Individuals with nondepth-coded tags displayed variation in the number of detections per day at their home receivers (Fig. S1), while fish with depth-coded tags showed persistent shifts in depth over time (Fig. 3). We cannot definitively attribute observed variation in daily detections 
Table 2. Watanabe-Akaike information criterion (WAIC) comparison for the different depth/size metric models. Based on WAIC, the model including condition factor as an explanatory variable had the greatest data support. The null model that excluded the effect of body size had the least support. These results provide evidence of a relationship between depth and size

\begin{tabular}{|lcc|}
\hline Model & $\begin{array}{l}\text { WAIC } \\
\text { value }\end{array}$ & $\begin{array}{l}\text { Akaike } \\
\text { weight }\end{array}$ \\
\hline glm(mean depth $\sim$ condition) & 40.50686 & 0.640 \\
glm(mean depth $\sim$ weight_kg) & 42.41804 & 0.246 \\
glm(mean depth $\sim$ length_cm) & 44.43859 & 0.090 \\
glm(mean depth 1) & 47.10647 & 0.024 \\
\hline
\end{tabular}

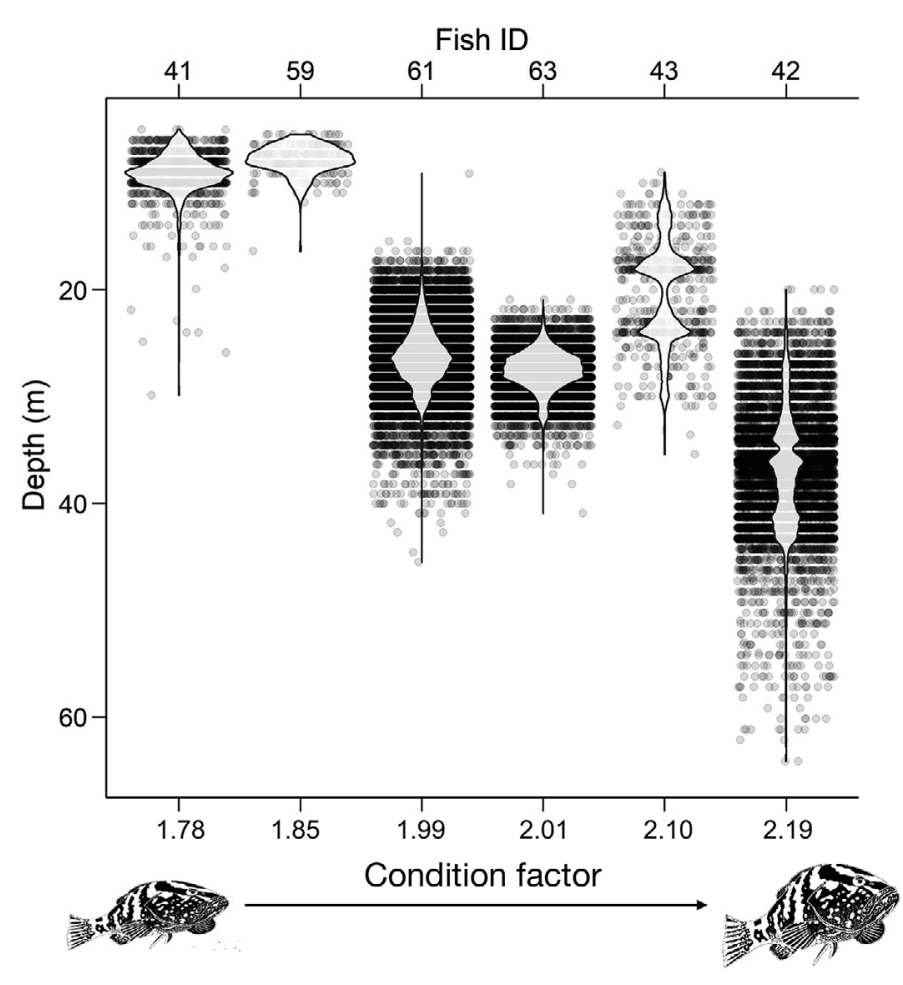

Fig. 6. Depth records at the home receiver for each fish with a depth-coded tag with an associated home receiver sorted from lowest to highest condition value. Bayesian linear regression analyses found a positive relationship between condition factor and depth. Raw depth records are displayed as points, while the distribution of the depth records for each fish is shown by the overlaid violin plot. Note that records for each fish are drawn from periods varying from months to years based on the length of time the fish was detected (see Fig. 4)

to a shift in activity center at home reef sites, but the comparison of daily detections and depth records in fish with depth-coded tags suggests that this is a reasonable assumption (Fig. 4). Most shifts in activity centers coincided with the return of fish to home reef sites after a spawning migration. This is indicative of post-spawning habitat selection on a smaller scale and within home reef sites.

Our findings of Nassau grouper diel activity agree with the prevailing description of large-bodied epinephelids as crepuscular hunters (Parrish 1987, Shpigel \& Fishelson 1989, Brulé et al. 1994, Sluka \& Sullivan 1996, Sluka 2000). The 7 individuals included in the vertical activity analysis displayed a higher likelihood of activity during the daylight side of crepuscular periods (Fig. 5b). Nassau grouper are known to form nuclear hunting relationships, following other species such as eel or octopus to capture prey they disturb (Diamant \& Shpigel 1985, Carter et al. 1994, Roberts et al. 1995). The use of this strategy suggests that vision could be important to coordinate hunting behavior during the day. Indeed, Carter et al. (1994) suggested that the daytime movement they observed in acoustically tagged individuals, which peaked during crepuscular time periods, could be a result of inter-specific hunting excursions. It is less clear why the magnitude of vertical activity does not display similar patterns as the probability of activity (Fig. 5a). It could simply be an artifact of our small sample size. An alternative explanation is that the low resolution of the depth data reported by the tags $(\sim 1 \mathrm{~m})$ coupled with the generally limited vertical movement of these demersal fish makes it difficult to detect changes in the magnitude of vertical activity.

The positive relationship between depth and condition factor for depth-tagged fish with home receivers suggests that different sized Nassau grouper partition their home reef sites along a depth gradient. It should be noted that the sample size for this portion of our analysis was small ( $\mathrm{n}=6)$, and we assumed that individuals maintained the same body condition throughout the sampling period. While further investigation of these relationships is warranted, we are confident in the relationship we found between depth and condition. Fish rarely lose length, and given the performance of the models we tested (Table 2), there is sufficient evidence to suggest there is a relationship between fish condition and depths occupied at home reef sites. This finding aligns with anecdotal reports in previous studies that larger Nassau grouper tend to occur in deeper, high relief areas of the reef (Randall 1962, Sadovy \& Eklund 1999, Semmens et al. 2007, Legare et al. 2011).

It is not entirely clear why higher condition individuals tend to occupy deeper habitat, although a positive relationship between depth and size has been documented for other fishes (Mccormick 1989, Lowry \& Suthers 1998). One hypothesis is that fishery impacts led to the deepening of higher condition indi- 


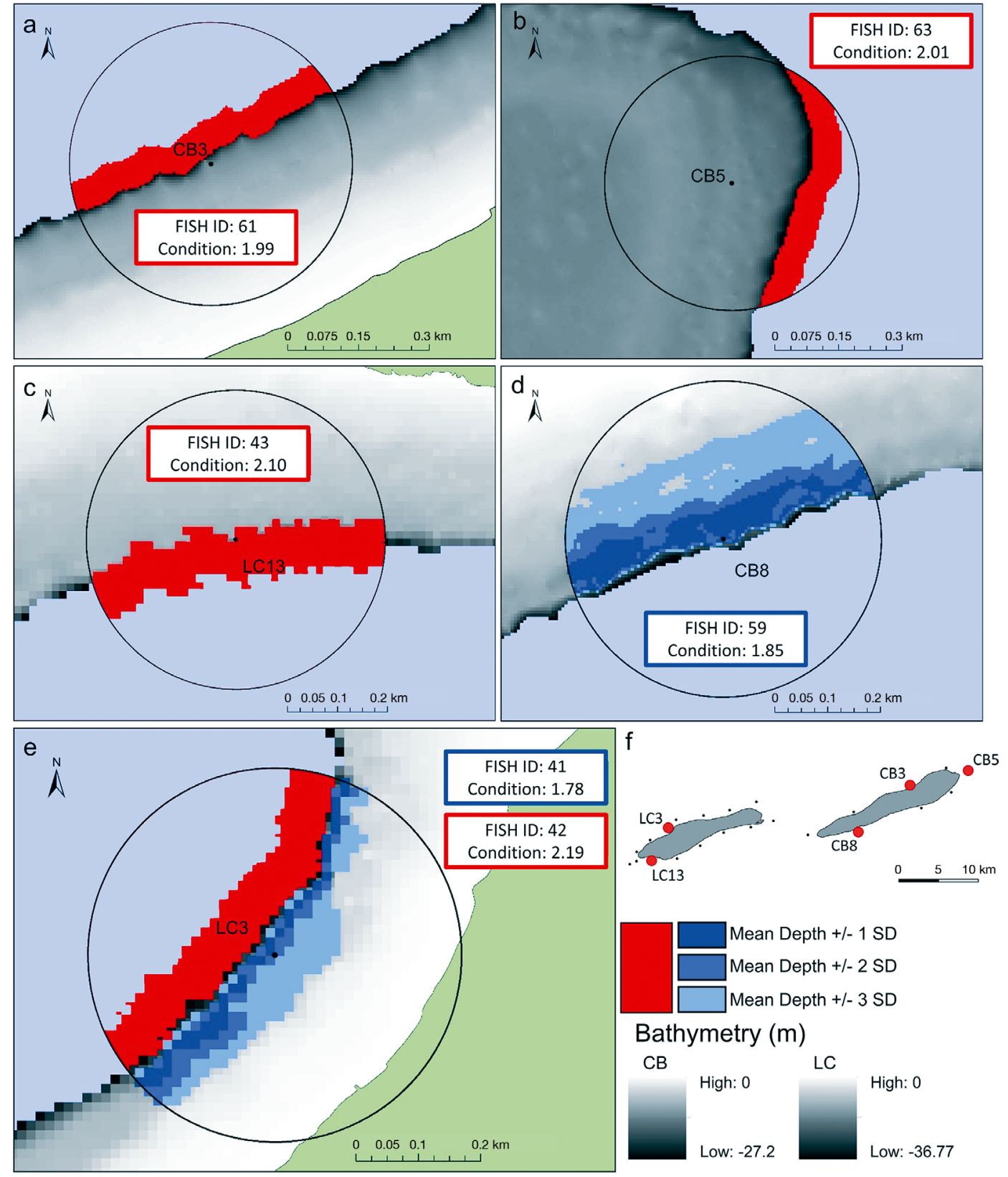

Fig. 7. Estimated regions occupied by fish with depth-coded tags at their home receivers $(\mathrm{n}=6)$. The home receiver and its $320 \mathrm{~m}$ detection range is shown by the black point and the circle surrounding it. Areas exceeding the available bathymetry data are shown in light blue, and land areas are shown in green. (a,b,c,e) Four fish (IDs 42, 43, 61, and 63) occupied areas beyond the bounds of the available bathymetry data. We assumed that these fish were equally likely to occur along the reef shelf in the deeper areas farther from shore within the detection range of their home receiver (red bands). (d,e) For the other 2 fish (IDs 41 and 59), we color coded the areas within the detection range of the home receiver based on their depth detections (blue scale). (f) Legend panel. LC: Little Cayman; CB: Cayman Brac; red dots: home receivers

viduals, with fishers selectively harvesting fish in shallower areas resulting in a disproportionate amount of larger individuals at depth (Frank et al. 2018). Alternatively, Semmens et al. (2008) suggested that Nassau grouper might continue to undergo ontogenetic sorting as adults, establishing deeper territories as they grow. It is possible that the increase in depth with size is an artifact of the preference for habitat along the reef edge, which is generally deeper. Many studies on reef fish show that reef relief and rugosity can strongly influence species diversity and size (e.g. Risk 1972, Luckhurst \& Luckhurst 1978, Gratwicke \& Speight 2005, Semmens et al. 2005, Harborne et al. 2012, Farmer \& Ault 2018). These studies suggest that 
more complex reef structures allow for a greater diversity of prey and ample shelter, which benefits predators such as the Nassau grouper. Accordingly, Bolden (2001) found that resource availability, particularly habitat and prey availability, has the greatest influence over home reef site size in Nassau grouper. It is likely the high relief of deeper reef edge environments is beneficial, because it provides more diverse structure across a range of depths that support a variety of prey items and facilitate effective sheltering for the Nassau grouper themselves (Hixon \& Beets 1993, Almany 2004).

In our study, we characterized the persistence of fish on specific reef areas as home reef sites rather than territories, because it is not clear to what extent tagged grouper are excluding conspecifics from home reef sites. In general, Nassau grouper are thought to increase territoriality as they mature, with larger fish less likely to share habitat and occupying distinct home reef sites with little overlap (Legare et al. 2011). Records of interactions between individuals outside of spawning season indicate that larger adults are more dominant (Sadovy \& Eklund 1999). In the instance in which two of our fish with depthcoded tags maintained home reef sites at the same home receiver, the fish with the higher body condition occupied deeper habitat and our analysis indicated no spatial overlap with the other individual (Fig. 7e). While these findings cannot alone be interpreted as strong evidence of territoriality, they nonetheless support the predominant theory of territoriality in Nassau grouper (Diamant \& Shpigel 1985, Sadovy \& Eklund 1999, Legare et al. 2011, Archer et al. 2012). Combined with the positive relationship between depth and condition of tagged fish, these results suggest that higher condition individuals could preferentially occupy deeper habitats along the reef edge and exclude smaller individuals from this higher quality habitat. In terms of conservation and management, if Nassau grouper do maintain distinct territories, as the 2 individuals with the same home receiver in our mapping analysis suggest, measures such as area closures will need to be large enough to encompass multiple individual territories. Further research into the size and nature of territories of Nassau grouper will better inform different spatial management strategies at home reef sites.

Our tracking of 20 individuals across multiple years allowed us to verify previous notions of high site fidelity among Nassau grouper to home reef sites (Sadovy \& Eklund 1999, Bolden 2000, Legare et al. 2011, Dahlgren et al. 2016). We found that no fish moved between Cayman Brac and Little Cayman, despite the fact that Nassau grouper are capable of traveling much longer distances (Carter et al. 1994, Bolden 2000). Starr et al. (2007) found similar results, with no fish leaving their study atoll in Belize, and suggested that post-settlement Nassau grouper are unlikely to travel over deep water and require contiguous reef structures to migrate. They suggested that this is why large-scale spawning migrations of the species (hundreds of kilometers) only occur in barrier reef systems or island chains linked by shallow water (Starr et al. 2007). This reasoning matches our findings as well, as Cayman Brac and Little Cayman are separated by depths greater than $300 \mathrm{~m}$ (Kobara \& Heyman 2008). Despite the fact that there was no movement between islands, the fish tagged in this study still participated in spawning migrations, traveling from home reef sites to spawning aggregation sites on the same island (our Fig. 1; Semmens et al. 2007). Similar to the findings of Dahlgren et al. (2016), individuals detected over multiple years that had a home receiver consistently returned to the same location after migrating to aggregation sites during the spawning season (Semmens et al. 2007). The consistency of returning to and maintaining residence at home reef sites over long periods indicates that individuals likely gain a lasting advantage from continuously occupying the same area (Börger et al. 2008, Shima et al. 2012). In the context of spatial protections such as MPAs, the persistence of home reef sites suggests that individuals in protected areas will remain protected for a majority, if not all of their reproductive-aged life. In the broader context of spawning migrations and home reef behavior, our findings suggest that local management efforts will be most effective at supporting Nassau grouper recovery, because their movements are limited by the availability of contiguous shallow reefs and high site fidelity to home reef sites. High site fidelity to spawning aggregation sites has also been reported for Nassau grouper (Semmens et al. 2007, Starr et al. 2007, Dahlgren et al. 2016). Combining protection of home reefs with existing protections of spawning aggregation sites would likely support both increased density and a disproportionate boost to fecundity, because of the stable nature of these 2 critical spatial areas in Nassau grouper life history (Peters 1983, Thresher 1984, Roberts \& Polunin 1991, Sadovy 1996).

Understanding the spatial ecology of Nassau grouper is important for fisheries management and the management of Caribbean reef ecosystems. As the health of Caribbean reef systems continues to decline due to myriad stressors, including fishing pressure, invasive species, and climate change, con- 
serving culturally, economically, and ecologically key species like the Nassau grouper is increasingly crucial (Carter et al. 1994, Rudd \& Tupper 2002, Stallings 2008, Legare et al. 2011). Most management of Nassau grouper populations focuses on protecting spawning aggregations; however, studies of tag return rates suggest high fishing mortality outside the spawning season (Sadovy \& Eklund 1999, Starr et al. 2007). Given that many stocks are struggling to recover (Sadovy 1999, Semmens et al. 2008, Sherman et al. 2016, Egerton et al. 2017, Sadovy de Mitcheson 2020), management strategies for non-spawning periods will likely be a critical component to successful conservation and management of this species.

While we found that activity centers within home reef sites can shift through time, the general location of home reef sites was remarkably consistent. The finding of persistent home reef sites across years suggests that properly sized and positioned spatial reserves will likely succeed at protecting individuals at home reefs as they mature and build fecundity. The apparent preference for high relief regions along the reef edge suggests that any home reef spatial closures, at least in this system, should include habitat with these characteristics, and incorporate depth profile as a key descriptor of the closure. Nassau grouper habitats in other areas of the Caribbean that do not share the Cayman Islands' characteristic short shelves and sharp drop offs will likely require localized consideration of preferred bathymetric conditions for the species. The relationship between condition and depth suggests that restricting fishing depths may be an effective method of protecting larger, more fecund individuals, but further analysis on this topic is warranted and would likely strengthen this assertion. Future studies should target these research directions and potential management strategies to work towards establishing effective regulations to help Nassau grouper populations recover.

Acknowledgements. We thank the many research divers who have participated in and supported the REEF/DoE Grouper Moon Project. We also thank the generous support and logistical assistance provided by local Cayman businesses and residents (including, but not limited to, Little Cayman Beach Resort and Southern Cross Club). Funding was provided in part by the Lenfest Ocean Program, the Disney Conservation Fund, National Oceanic and Atmospheric Administration International Coral Reef Conservation Program Grant NA04NOS4630287, P. Hillenbrand, and the J. Edward Mahoney Foundation. Open access publication of this paper was supported by the Oregon State University Thomas G. Scott Publication Fund and the Cayman Islands Department of Environment.

\section{LITERATURE CITED}

Abecasis D, Bentes L, Erzini K (2009) Home range, residency and movements of Diplodus sargus and Diplodus vulgaris in a coastal lagoon: connectivity between nursery and adult habitats. Estuar Coast Shelf Sci 85:525-529

* Afonso P, Graça G, Berke G, Fontes J (2012) First observations on seamount habitat use of blackspot seabream (Pagellus bogaraveo) using acoustic telemetry. J Exp Mar Biol Ecol 436-437:1-10

Aguilar-Perera A (2006) Disappearance of a Nassau grouper spawning aggregation off the southern Mexican Caribbean coast. Mar Ecol Prog Ser 327:289-296

Almany GR (2004) Does increased habitat complexity reduce predation and competition in coral reef fish assemblages? Oikos 106:275-284

Andrews KS, Williams GD, Farrer D, Tolimieri N, Harvey CJ, Bargmann G, Levin PS (2009) Diel activity patterns of sixgill sharks, Hexanchus griseus: the ups and downs of an apex predator. Anim Behav 78:525-536

Archer SK, Heppell SA, Semmens BX, Pattengill-Semmens CV, Bush PG, Mccoy CM, Johnson BC (2012) Patterns of color phase indicate spawn timing at a Nassau grouper Epinephelus striatus spawning aggregation. Curr Zool 58:73-83

*Bardach JE (1958) On the movements of certain Bermuda reef fishes. Ecology 39:139-146

Benedetti LS (2013) Marine protected areas (MPAS) as a fisheries management tool for the Nassau grouper (Epinephelus striatus) in Belize. MSc thesis, Ryerson University, Toronto, Ontario

Bolden SK (2000) Long-distance movement of a Nassau grouper (Epinephelus striatus) to a spawning aggregation in the central Bahamas. Fish Bull 98:642-645

Bolden S (2001) Using ultrasonic telemetry to determine home range of a coral-reef fish. In: Sibert JR, Nielsen JL (eds) Electronic tagging and tracking in marine fisheries. Springer, Dordrecht, p 167-188

Börger L, Dalziel BD, Fryxell JM (2008) Are there general mechanisms of animal home range behaviour? A review and prospects for future research. Ecol Lett 11:637-650

Brulé T, Avila D, Crespo M, Déniel C (1994) Seasonal and diel changes in diet composition of juvenile red grouper (Epinephelus morio) from Campeche Bank. Bull Mar Sci 55:255-262

*Burt WH (1943) Territoriality and home range concepts as applied to mammals. J Mammal 24:346-352

Bush PG, Lane ED, Ebanks-Petrie GC, Luke K and others (2006) The Nassau grouper spawning aggregation fishery of the Cayman Islands - an historical and management perspective. Proc Gulf Caribb Fish Inst 57:515-524

Carter J, Marrow G, Pryor V (1994) Aspects of the ecology and reproduction of Nassau grouper (Epinephelus striatus) off the coast of Belize, Central America. Proc Gulf Caribb Fish Inst 43:65-111

* Chiappone M, Sluka R, Sealey KS (2000) Groupers (Pisces: Serranidae) in fished and protected areas of the Florida Keys, Bahamas and northern Caribbean. Mar Ecol Prog Ser 198:261-272

Claydon JAB, Kroetz AM (2008) The distribution of early juvenile groupers around South Caicos, Turks and Caicos Islands. Proc Gulf Caribb Fish Inst 60:345-350

* Crossin GT, Heupel MR, Holbrook CM, Hussey NE and others (2017) Acoustic telemetry and fisheries management. Ecol Appl 27:1031-1049 
Dahlgren CP, Buch K, Rechisky E, Hixon MA (2016) Multiyear tracking of Nassau grouper spawning migrations. Mar Coast Fish 8:522-535

* Diamant A, Shpigel M (1985) Interspecific feeding associations of groupers (Teleostei: Serranidae) with octopuses and moray eels in the Gulf of Eilat (Agaba). Environ Biol Fishes 13:153-159

Egerton JP, Johnson AF, Le Vay L, McCoy CM, Semmens BX, Heppell SA, Turner JR (2017) Hydroacoustics for the discovery and quantification of Nassau grouper (Epinephelus striatus) spawning aggregations. Coral Reefs 36:589-600

Farmer NA, Ault JS (2018) Accounting for detection gaps when evaluating reef fish habitat use in an acoustic array. Can J Fish Aquat Sci 75:375-388

Fontes J, Schmiing M, Afonso P (2014) Permanent aggregations of a pelagic predator at shallow seamounts. Mar Biol 161:1349-1360

Frank KT, Petrie B, Leggett WC, Boyce DG (2018) Exploitation drives an ontogenetic-like deepening in marine fish. Proc Natl Acad Sci USA 115:6422-6427

Gelman A, Rubin DB (1992) A single series from the Gibbs sampler provides a false sense of security. In: Bernardo JM, Berger JO, Dawid AP, Smith AFM (eds) Bayesian statistics 4. Oxford University Press, New York, NY, p 625-631

Gerking SD (1953) Evidence for the concepts of home range and territory in stream fshes. Ecology 34:347-365

* Gratwicke B, Speight MR (2005) The relationship between fish species richness, abundance and habitat complexity in a range of shallow tropical marine habitats. J Fish Biol 66:650-667

* Grüss A, Robinson J, Heppell SS, Heppell SA, Semmens BX (2014) Conservation and fisheries effects of spawning aggregation marine protected areas: what we know, where we should go, and what we need to get there. ICES J Mar Sci 71:1515-1534

Harborne AR, Mumby PJ, Ferrari R (2012) The effectiveness of different meso-scale rugosity metrics for predicting intra-habitat variation in coral-reef fish assemblages. Environ Biol Fishes 94:431-442

Hayne DW (1949) Calculation of size of home range. J Mammal 30:1-18

Heyman WD, Kobara S (2012) Geomorphology of reef fish spawning aggregations in Belize and the Cayman Islands (Caribbean). In: Harris PT, Baker EK (eds) Seafloor geomorphology as benthic habitat. Elsevier, London and Waltham, MA, p 387-396

Hixon MA, Beets JP (1989) Shelter characteristics and Caribbean fish assemblages: experiments with artificial reefs. Bull Mar Sci 44:666-680

Hixon MA, Beets JP (1993) Predation, prey refuges, and the structure of coral-reef fish assemblages. Ecol Monogr 63: 77-101

Holts D, Bedford D (1993) Horizontal and vertical movements of the shortfin mako shark, Isurus oxyrinchus, in the Southern California Bight. Mar Freshw Res 44:901-909

Huveneers C, Simpfendorfer CA, Kim S, Semmens JM and others (2016) The influence of environmental parameters on the performance and detection range of acoustic receivers. Methods Ecol Evol 7:825-835

Jackson AM, Semmens BX, Sadovy de Mitcheson Y, Nemeth RS and others (2014) Population structure and phylogeography in Nassau grouper (Epinephelus striatus), a mass-aggregating marine fish. PLOS ONE 9: e97508
Kadison E, Nemeth RS, Blondeau J, Smith T, Calnan J (2010) Nassau grouper (Epinephelus striatus) in St. Thomas, US Virgin Islands, with evidence for a spawning aggregation site recovery. Proc Gulf Caribb Fish Inst 62:273-279

Khan JA, Goatley CHR, Brandl SJ, Tebbett SB, Bellwood DR (2017) Shelter use by large reef fishes: long-term occupancy and the impacts of disturbance. Coral Reefs 36 : 1123-1132

Kobara S, Heyman WD (2008) Geomorphometric patterns of Nassau grouper (Epinephelus striatus) spawning aggregation sites in the Cayman Islands. Mar Geod 31:231-245

Korner-Nievergelt F, Roth T, Felten S, Guelat J, Almasi B, Korner-Nievergelt P (2015) Bayesian data analysis in ecology using linear models with R, BUGS and Stan. Elsevier, London

Kramer DL, Chapman MR (1999) Implications of fish home range size and relocation for marine reserve function. Environ Biol Fishes 55:65-79

Legare B, Maize K, Nemeth R (2011) Juvenile Nassau grouper (Epinephelus striatus) utilization of nearshore habitats with evidence of adult connectivity to a spawning aggregation site. Proc Gulf Caribb Fish Inst 63: 198-199

K Lowry MB, Suthers IM (1998) Home range, activity and distribution patterns of a temperate rock-reef fish, Cheilodactylus fuscus. Mar Biol 132:569-578

* Luckhurst BE, Luckhurst K (1978) Analysis of the influence of substrate variables on coral reef fish communities. Mar Biol 49:317-323

*Maher CR, Lott DF (2000) A review of ecological determinants of territoriality within vertebrate species. Am Midl Nat 143:1-29

* Mathies NH, Ogburn MB, McFall G, Fangman S (2014) Environmental interference factors affecting detection range in acoustic telemetry studies using fixed receiver arrays. Mar Ecol Prog Ser 495:27-38

Matthews KR (1990) An experimental study of the habitat preferences and movement patterns of copper, quillback, and brown rockfishes (Sebastes spp.). Environ Biol Fishes 29:161-178

Mccormick MI (1989) Spatio-temporal patterns in the abundance and population structure of a large temperate reef fish. Mar Ecol Prog Ser 53:215-225

McKay Curtis S (2018) mcmcplots: Create Plots from MCMC Output. R package version 0.4.3. https://CRAN.R-project. org $/$ package $=$ mcmcplots

Pangle KL, Sutton TM (2005) Temporal changes in the relationship between condition indices and proximate composition of juvenile Coregonus artedi. J Fish Biol 66: 1060-1072

Parrish JD (1987) The trophic biology of snappers and groupers. Polovina JJ, Ralston S (eds) Tropical snappers and groupers: biology and fisheries management. Westview Press, Boulder, CO, p 405-463

Parsons DM, Babcock RC, Hankin RKS, Willis TJ, Aitken JP, O'Dor RK, Jackson GD (2003) Snapper Pagrus auratus (Sparidae) home range dynamics: acoustic tagging studies in a marine reserve. Mar Ecol Prog Ser 262:253-265

Peters R (1983) The ecological implications of body size. Cambridge University Press, Cambridge

Pillans RD, Babcock RC, Thomson DP, Haywood MDE, Downie RA, Vanderklift MA, Rochester WA (2017) Habitat effects on home range and schooling behaviour in a herbivorous fish (Kyphosus bigibbus) revealed by acoustic tracking. Mar Freshw Res 68:1454-1467 
Plummer M (2003) JAGS: a program for analysis of Bayesian graphical models using Gibbs sampling. Proceedings of the 3rd international workshop on distributed statistical computing Vol 124. No. 125:1-10

Plummer M, Stukalov A, Denwood M (2019) Rjags: Bayesian graphical models using MCMC. https://CRAN.R-project. org/web/packages/rjags/rjags.pdf

R Core Team (2019) R: a language and environment for statistical computing. R foundation for statistical computing, Vienna. www.R-project.org/

Randall JE (1962) Tagging reef fishes in the Virgin Islands. Proc Gulf Caribb Fish Inst 14:201-241

Ricker WE (1975) Computation and interpretation of biological statistics of fish populations. Bull Fish Res Board Can 191:1-382

Risk MJ (1972) Fish diversity on a coral reef in the Virgin Islands. Atoll Res Bull 153:1-4

Roberts C, Polunin N (1991) Are marine reserves effective in management of reef fisheries? Rev Fish Biol Fish 1:65-91

Roberts CM, Quinn N, Tucker JW Jr, Woodward PN (1995) Introduction of hatchery-reared Nassau grouper to a coral reef environment. N Am J Fish Manage 15:159-164

Robinson ML, Gomez-Raya L, Rauw WM, Peacock MM (2008) Fulton's body condition factor $K$ correlates with survival time in a thermal challenge experiment in juvenile Lahontan cutthroat trout (Oncorhynchus clarki henshawi). J Therm Biol 33:363-368

Rounsefell GA, Kask JL (1945) How to mark fish. Trans Am Fish Soc 73:320-363

Rudd MA, Tupper MH (2002) The impact of Nassau grouper size and abundance on scuba diver site selection and MPA economics. Coast Manage 30:133-151

Sadovy YJ (1996) Reproduction of reef fishery species. In: Polunin NVC, Roberts CM (eds) Reef fisheries. Chapman \& Hall Fish and Fisheries Series, Vol 20. Springer, Dordrecht, p 15-59

Sadovy Y (1999) The case of the disappearing grouper: Epinephelus striatus, the Nassau grouper, in the Caribbean and western Atlantic. Proc Gulf Caribb Fish Inst 45:5-22

Sadovy Y, Eklund AM (1999) Synopsis of biological data on the Nassau grouper, Epinephelus striatus (Bloch, 1792), and the jewfish, E. itajara (Lichtenstein, 1822). NOAA Technical Report NMFS 146, FAO Fisheries Synopsis 157

Sadovy YJ, Aguilar-Perera A, Sosa-Cordero E (2018) Epinephelus striatus. The IUCN Red List of Threatened Species 2018:e.T7862A46909843

Sadovy de Mitcheson Y (2020) Island of hope for the threatened Nassau grouper. Proc Natl Acad Sci USA 117: 2243-2244

Sala E, Ballesteros E, Starr RM (2001) Rapid decline of Nassau grouper spawning aggregations in Belize: fishery management and conservation needs. Fisheries 26:23-30

Semmens BX, Brumbaugh DR, Drew JA (2005) Interpreting space use and behavior of blue tang, Acanthurus coeruleus, in the context of habitat, density, and intraspecific interactions. Environ Biol Fishes 74:99-107

Semmens BX, Luke KE, Bush PG, McCoy CMR, Johnson BC (2006) Isopod infestation of postspawning Nassau grouper around Little Cayman Island. J Fish Biol 69:933-937

Semmens BX, Luke KE, Bush PG, Pattengill-Semmens C, Johnson B, Mccoy C, Heppell S (2007) Investigating the reproductive migration and spatial ecology of Nassau grouper (Epinephelus striatus) on Little Cayman Island

Editorial responsibility: Elliott Hazen,

Pacific Grove, California, USA

Reviewed by: A. Aguilar-Perera and 2 anonymous referees using acoustic tags - an overview. Proc Gulf Caribb Fish Inst 58:191-198

Semmens BX, Bush P, Heppell S, Johnson B, McCoy C, Pattengill-Semmens C, Whaylen L (2008) Charting a course for Nassau grouper recovery in the Caribbean: what we've learned and what we still need to know. Proc Gulf Caribb Fish Inst 60:607-609

Shapiro DY, Garcia-Moliner G, Sadovy Y (1994) Social system of an inshore stock of the red hind grouper, Epinephelus guttatus (Pisces: Serranidae). In: Balon EK, Bruton MN, Noakes DLG (eds) Women in ichthyology: an anthology in honour of ET, Ro and Genie. Springer, Dordrecht, p 415-422

Sherman KD, Dahlgren CP, Stevens JR, Tyler CR (2016) Integrating population biology into conservation management for endangered Nassau grouper Epinephelus striatus. Mar Ecol Prog Ser 554:263-280

Shima JS, Mcnaughtan D, Geange SW, Wilkinson S (2012) Ontogenetic variation in site fidelity and homing behaviour of a temperate reef fish. J Exp Mar Biol Ecol 416-417:162-167

Shpigel M, Fishelson L (1989) Food habits and prey selection of three species of groupers from the genus Cephalopholis (Serranidae: Teleostei). Environ Biol Fishes 24:67-73

Sluka RD (2000) Grouper and napoleon wrasse ecology in Laamu Atoll, Republic of Maldives: Part 1. Habitat, behavior, and movement patterns. Atoll Res Bull 491:1-26

Sluka R, Sullivan K (1996) Daily activity patterns of groupers in the Exuma Cays Land and Sea Park, central Bahamas. Bahamas J Sci 3:17-22

Smith CL (1961) Synopsis of biological data on groupers (Epinephelus and allied genera) of the western North Atlantic). FAO Fish Biol Synopsis 23, FAO, Rome

Stallings CD (2008) Indirect effects of an exploited predator on recruitment of coral-reef fishes. Ecology 89: 2090-2095

Starr RM, Sala E, Ballesteros E, Zabala M (2007) Spatial dynamics of the Nassau grouper Epinephelus striatus in a Caribbean atoll. Mar Ecol Prog Ser 343:239-249

* Stefánsson G (1996) Analysis of groundfish survey abundance data: combining the GLM and delta approaches. ICES J Mar Sci 53:577-588

* Stump K, Dahlgren C, Sherman K, Knapp C (2017) Nassau grouper migration patterns during full moon suggest collapsed historic fish spawning aggregation and evidence of an undocumented aggregation. Bull Mar Sci 93:375-389

*Thorson JT, Ward EJ (2013) Accounting for space-time interactions in index standardization models. Fish Res 147: 426-433

Thresher RE (1984) Reproduction in reef fishes. T.F.H. Publications, British Crown Colony of Hong Kong, Neptune City, NJ

Topping DT, Lowe CG, Caselle JE (2005) Home range and habitat utilization of adult California sheephead, Semicossyphus pulcher (Labridae), in a temperate no-take marine reserve. Mar Biol 147:301-311

Waterhouse L, Heppell SA, Pattengill-Semmens CV, McCoy C, Bush P, Johnson BC, Semmens BX (2020) Recovery of critically endangered Nassau grouper (Epinephelus striatus) in the Cayman Islands following targeted conservation actions. Proc Natl Acad Sci USA 117:1587-1595

Zeller DC (1997) Home range and activity patterns of the coral trout Plectropomus leopardus (Serranidae). Mar Ecol Prog Ser 154:65-77

Submitted: March 9, 2020

Accepted: September 28, 2020

Proofs received from author(s): November 13, 2020 